\title{
PENGARUH PENGELASAN SMAW TERHADAP POROS SAMBUNG YANG TERDAPAT PADA MESIN PENCETAK BRIKET
}

\author{
Alfian hamsi, Mirza fachrezi Matondang \\ 'Universitas Sumatera Utara (USU) \\ E-mail : Alfian_hamsi@yahoo.com
}

\begin{abstract}
ABSTRAK
Teknologi produksi dengan menggunakan bahan baku logam, teknik penyambungan logam dengan pengelasan merupakan proses pengerjaan yang memegang peranan yang sangat penting. Poros sambung pada mesin pencetak briket adalah komponen penting yang mempunyai fungsi sebagai penerus tenaga mekanik dari output shaft reducer ke screw. Telah terjadi kegagalan yang diakibatkan oleh patahnya poros sambung tersebut. Penelitian ini dilakukan untuk mengetahui pengaruh proses pengelasan terhadap poros sambung dengan metode SMAW dengan menggunakan metode pengujian-pengujian mekanik yang sesuai yaitu pengujian tarik,puntir,dan kekerasan. Dimana bahan dari material yang merupakan jenis baja ST-37 dengan tujuan unuk mengetahui nilai kekuatan tarik, nilai kekerasan, dan nilai puntir dari base metal dan juga dari spesimen yang telah dilakukan pengelasan SMAW. Setelah itu menghitung nilai tegangan geser dan nilai tegangan geser yang di izinkan untuk mengetahui kelayakan dari poros yang telah dilas. Pada hasil studi ini didapat bahwa sifat mekanik dari pengelasan SMAW mengalami perubahan nilai kekerasan yaitu pada base metal 127,6 BHN dan pada spesimen yang telah di las 121 BHN, untuk nilai kekuatan tarik pada base metal 499,05 N/mm²,Sedangkan pada spesimen yang telah di las 405,03 N/mm ${ }^{2}$ dan untuk nilai puntir base metal 597,64 kgf/mm sedangkan pada spesimen yang telah dilas 666,18 kgf/mm. Dan untuk kelayakan poros sambung yang telah dilas poros sambung tersebut tidak layak untuk digunakan karena tegangan yang diberikan oleh mesin lebih besar yaitu $50,79 \mathrm{Kg} / \mathrm{mm}^{2}$ dari pada tegangan yang diizinkan yang dapat di terima oleh poros sambung sebesar $5,25 \mathrm{Kg} / \mathrm{mm}^{2}$.
\end{abstract}

Kata kunci: Pengelasan SMAW, Baja ST-37.

\section{I.PENDAHULUAN}

Saat ini teknik penyambungan logam di bidang pengelasan sudah berkembangpesat. Pada konstruksi yang menggunakan bahan baku logam, hampir sebagianbesar sambungannya dikerjakan dengan cara pengelasan. Pengelasan juga banyakdigunakan untuk pengerjaan konstruksi gedung, jembatan, perpipaan dan otomotif. Selain untuk penyambungan, proses las juga dapat digunakan untuk reparasi, misalnya untuk mengisi lubang - lubang pada coran, membuat lapisanpada perkakas, mempertebal bagian yang sudah aus dan reparasi lainnya. . Proses pengelasan dibedakan menjadi beberapa jenis, dan SMAW merupakan salah satu proses pengelasan yang umum digunakan, utamanya pada pengelasan singkat dalam produksi, pemeliharaan dan perbaikan, dan untuk bidang konstruksi. Seperti pada mesin pencetak briket pada proses penggunaan terjadi keretakan berupa pecah pada kopling, maka di perlukan pengelasan dari poros sambung terhadap gearbox dan mesin pencetak briket agar proses produksi tetap berjalan. 


\section{Tinjauan Pustaka}

\section{Shield Metal Arc Welding (SMAW)}

Las SMAW yang berasal dari kata Shield Metal Arc Welding adalah proses pengelasan yang menggunakan panas untuk mencairkan material dasar atau logam induk dan elektroda (kawat las). Panas tersebut ditimbulkan oleh lompatan ion listrik yang terjadi antara katoda dan anoda (ujung elektroda dan permukaan plat yang akan dilas). Panas yang timbul dari lompatan ion listrik ini besarnya dapat mencapai $4000^{\circ}$ sampai $4500^{\circ} \mathrm{C}$.

\section{Mesin Pencetak Briket}

Mesin pencetak briket arang adalah mesin yang digunakan untuk mencetak Arang kelapa. Dimana briket arang ini dapat menjadi bahan bakar alternatif karena harganya terjangkau dan daya bakarnya merata. Dimana proses pembuatan briket arang ini di mulai dari pembakaran batok kelapa Setelah itu masuk ke fase pengadonan bahan agar hasil nya merekat, setelah itu masuk ke fase pencacahan. Poros merupakan salah satu bagian yang terpenting dari setiap mesin. Hampir semua mesin meneruskan tenaga bersama-sama dengan putaran. Peranan utama dalam transmisi seperti itu dipegang oleh poros

\section{Hasil dan Analisa} Material)

Hasil Uji kekerasan Spesimen Sebelum Dan Sesudah Dilakukan Pengelasan ( Raw

a. Sebelum Pengelasan

\begin{tabular}{|l|l|l|}
\hline $\begin{array}{l}\text { Daerah } \\
\text { Spesimen }\end{array}$ & $\begin{array}{l}\text { Diameter } \\
\text { indentasi }\end{array}$ & $\begin{array}{l}\text { Nilai } \\
\text { Kekerasan } \\
\text { (BHN) }\end{array}$ \\
\hline Las & $3,5 \mathrm{~mm}$ & $151 \mathrm{BHN}$ \\
\hline Haz & $3,5 \mathrm{~mm}$ & $151 \mathrm{BHN}$ \\
\hline Base Metal & $3,8 \mathrm{~mm}$ & $127 \mathrm{BHN}$ \\
\hline
\end{tabular}

b. Sesudah Pengelasan

\begin{tabular}{|l|l|l|}
\hline $\begin{array}{l}\text { Daerah } \\
\text { Spesimen }\end{array}$ & $\begin{array}{l}\text { Diameter } \\
\text { indentasi }\end{array}$ & $\begin{array}{l}\text { Nilai } \\
\text { Kekerasan } \\
\text { (BHN) }\end{array}$ \\
\hline Titik Las & $3,8 \mathrm{~mm}$ & $121 \mathrm{BHN}$ \\
\hline HAZ & $3,9 \mathrm{~mm}$ & $127 \mathrm{BHN}$ \\
\hline Base Metal & $3,7 \mathrm{~mm}$ & $135 \mathrm{BHN}$ \\
\hline
\end{tabular}

\section{Hasil Uji Tarik}

Data hasil uji tarik spesimen sebelum dilakukan pengelasan (raw material)

\begin{tabular}{|c|c|c|c|c|c|c|}
\hline Spesimen & No. uji & Diameter $(\mathrm{mm})$ & P awal $(\mathrm{mm})$ & P akhir $(\mathrm{mm})$ & Luas $\left(\mathrm{mm}^{2)}\right.$ & $\mathrm{P}(\mathrm{N})$ \\
\hline 1 & 1 & 8,91 & 56.64 & 70,04 & 62,31 & 31153 \\
\hline 2 & 1 & 8,91 & 56,20 & 69,63 & 62,31 & 31032 \\
& & & & & & \\
\hline
\end{tabular}




\begin{tabular}{|l|l|l|l|l|l|l|}
\hline 3 & 1 & 8,91 & 56,45 & 70,01 & 62,31 & 31105 \\
\hline
\end{tabular}

Data hasil uji tarik spesimen setelah dilakukan pengelasan

\begin{tabular}{|c|c|c|c|c|c|c|}
\hline Spesimen & No. uji & Diameter $(\mathrm{mm})$ & $\mathrm{P}$ awal $(\mathrm{mm})$ & $\mathrm{P}$ akhir $(\mathrm{mm})$ & Luas $\left(\mathrm{mm}^{2)}\right.$ & $\mathrm{P}(\mathrm{N})$ \\
\hline 1 & 1 & 9,31 & 100 & 117,82 & 68,04 & 27550 \\
\hline 2 & 1 & 9,59 & 100 & 118,71 & 72,19 & 29000 \\
\hline 3 & 1 & 9,21 & 100 & 119,94 & 66,58 & 27200 \\
& & & & & & \\
\hline
\end{tabular}

Nilai tegangan untuk masing-masing spesimen sebelum dan sesudah dilakukan pengelasan adalah:
a.Sebelum Pengelasan
b. Sesudah Pengelasan

\begin{tabular}{|c|c|c|c|c|}
\hline Spesimen & $\begin{array}{c}\text { No. } \\
\text { uji }\end{array}$ & $\begin{array}{c}\text { Luas } \\
\left(\mathrm{mm}^{2}\right)\end{array}$ & $\mathrm{P}(\mathrm{N})$ & $\begin{array}{c}\sigma \\
\left(\mathrm{N} / \mathrm{mm}^{2}\right)\end{array}$ \\
\hline 1 & 1 & 62,31 & 31153 & 499,96 \\
\hline 2 & 2 & 62,31 & 31032 & 498,02 \\
\hline 3 & 3 & 62,31 & 31105 & 499,19 \\
\hline
\end{tabular}

\begin{tabular}{|c|c|c|c|c|}
\hline Spesimen & $\begin{array}{c}\text { No. } \\
\text { uji }\end{array}$ & $\begin{array}{c}\text { Luas } \\
\left(\mathrm{mm}^{2}\right)\end{array}$ & $\mathrm{P}(\mathrm{N})$ & $\begin{array}{c}\sigma \\
\left(\mathrm{N} / \mathrm{mm}^{2}\right)\end{array}$ \\
\hline 1 & 1 & 68,04 & 27550 & 404,90 \\
\hline 2 & 2 & 72,19 & 29000 & 401,69 \\
\hline 3 & 3 & 66,58 & 27200 & 405,03 \\
\hline
\end{tabular}

Adapun diagram tegangan dari data hasil pengujian tarik sebelum dilakukan pengelasan dapat dilihat pada gambar

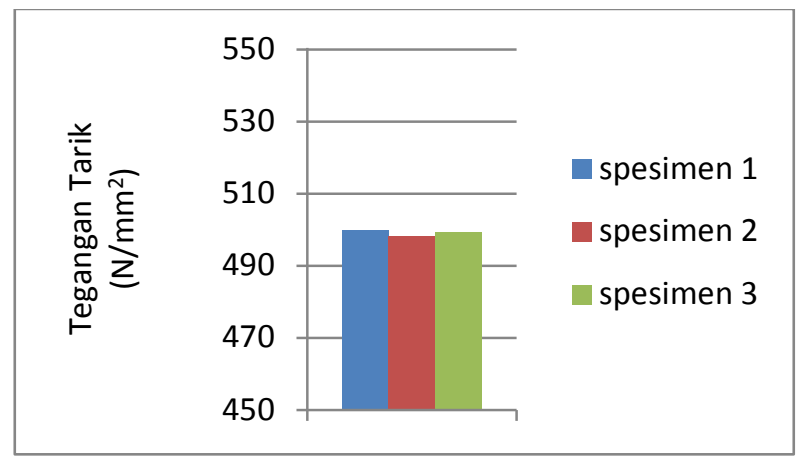


Adapun diagram tegangan dari data hasil pengujian tarik dapat dilihat pada gambar

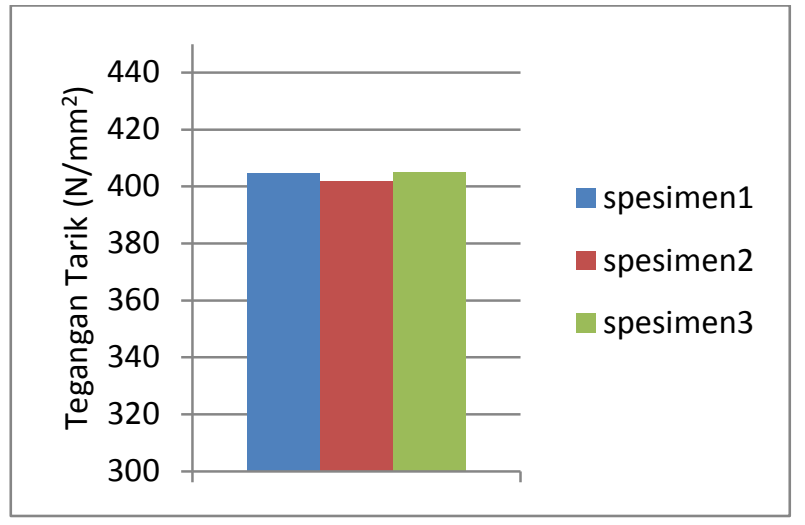

\section{Hasil Uji Puntir}

Nilai Hasil Pengujian Puntir Spesimen Sebelum dilakukan Pengelasan (raw material)

\begin{tabular}{|c|c|l|l|l|}
\hline Spesimen & No. & $\begin{array}{l}\text { Torsion } \\
(\text { kgf-cm })\end{array}$ & Sudut(deg) & Putaran \\
\hline 1 & 1 & 582.78 & 1379 & 3,83 \\
\hline 2 & 2 & 614.86 & 1314 & 3,65 \\
\hline 3 & 3 & 595,30 & 1433 & 3,98 \\
\hline & Rata-rata & 597,64 & 1375 & 3,82 \\
\hline
\end{tabular}

Nilai Hasil Pengujian Puntir Spesimen Sesudah Pengelasan

\begin{tabular}{|c|c|c|c|c|}
\hline Spesimen & No. & Torsion (kgf-cm) & Sudut (deg) & Putaran(rev) \\
\hline 1 & 1 & 734.04 & 1037 & 2,88 \\
\hline 2 & 2 & 649.06 & 1194 & 3,32 \\
\hline 3 & 3 & 615.45 & 1586 & 4,41 \\
\hline & Rata-rata & $\mathbf{6 6 6 , 1 8}$ & $\mathbf{1 2 7 2 , 3 3}$ & $\mathbf{3}, 53$ \\
\hline
\end{tabular}

\section{Perhitungan Pada Mesin Pencetak Briket}

Pada mesin pencetak briket mesin diesel atau mesin penggerak yang digunakan berkekuatan 8 hp dengan 3500 rpm sedangkan untuk reducer menggunakan ratio $10: 1$

\section{Daya Dan Momen}

Motor yang digunakan adalah motor listrik dengan daya $4 \mathrm{hp}$

$$
\mathrm{P}=4 \mathrm{hp}=2,9828 \mathrm{~kW} \quad \mathrm{Pd} \quad=\text { Fc } \times \mathrm{P}
$$




$$
\text { Putaran : } \mathrm{n}_{2}=\mathrm{n}=2620 \quad \mathrm{Pd}=1,2 \times 2,9828=3579 \mathrm{~W}
$$

Perhitungan momen puntir yang dikerjakan pada poros

$$
\mathrm{Mp}=9,74 \times 10^{5} \underline{\mathrm{Pd}}=9959 \mathrm{~kg} \mathrm{~mm}
$$

.Perhitungan tegangan geser :

$\tau \mathrm{g}=5,1 \mathrm{Mp} / \mathrm{d}^{3} \mathrm{~s} \mathrm{Tg}=\underline{5,1 \times 9969 \mathrm{~kg} \cdot \mathrm{mm}}=50,79 \mathrm{~kg} / \mathrm{mm}^{2}$

$$
10^{3}
$$

Perhitungan tegangan geser yang dizinkan :

$$
\mathrm{Ta}=\sigma \mathrm{b} / \mathrm{Sf} 1 \mathrm{xSf} 2=5,25 \mathrm{~kg} / \mathrm{mm}^{2}
$$

Dengan demikian poros yang digunakan tidak sesuai kapasitas beban kerja, jadi poros yang sesuai beban kerja adalah jenis baja AISI 1040 karena kekuatan tariknya sebesar $55 \mathrm{~kg} / \mathrm{mm}^{2}$ atau sebesar 539,36 N/mm².

\section{KESIMPULAN}

Dari hasil pengujian dan analisa yang dilakukan dapat diambil kesimpulan :

Setelah dilakukan pengujian dan perhitungan mengenai kelayakan poros sambung yang telah melewati proses pengelasan, poros sambung tersebut tidak layak untuk digunakan karena tegangan yang diberikan oleh mesin lebih besar yaitu $50,79 \mathrm{~kg} / \mathrm{mm}^{2}$ dari pada tegangan yang diizinkan yang dapat di terima oleh poros sambung sebesar $5,25 \mathrm{~kg} / \mathrm{mm}^{2}$. Sehingga kegagalan yang terjadi pada poros dikarenakan oleh material poros yang tidak sanggup untuk mentransmisikan beban yang diberikan. Dengan demikian poros yang digunakan tidak sesuai kapasitas beban kerja, jadi poros yang sesuai beban kerja adalah jenis baja AISI 1040 karena kekuatan tariknya sebesar $55 \mathrm{~kg} / \mathrm{mm}^{2}$.

Dari hasil pengujian poros sambung yang telah dilas, sifat mekanik mengalami penurunan dari poros sambung tanpa pengelasan. Dimana nilai kekuatan tarik rata - rata pada raw material yaitu sebesar 499,05 N/mm² sedangkan pada spesimen poros yang telah dilas nilai rata-rata kekuatan tarik sebesar 405,03 N/ $\mathrm{mm}^{2}$. Pada pengujian kekerasan,nilai kekerasan raw material pada daerah las sebesar 151 BHN, sedangkan pada spesimen yang telah dilas nilai kekerasan di daerah las sebesar 121 BHN. Pada pegujian puntir nilai torsi rata rata pada raw material sebesar 597,64 kgf-cm sedangkan nilai torsi rata rata spesimen yang telah dilas sebesar 666,18 kgf-cm. 


\section{DAFTAR PUSTAKA}

[1]Wiryosumarto, H, Okumurha T.,2004, Teknologi Pengelasan logam,cetakan ke8 ,Pradnya Paramita, Jakarta.

[2]Sri Widharto, 2003. Petunjuk Kerja Las, Cetakan-5, Jakarta, Pradnya Paramita.

[3]George E.Dieter,1987,Mechanical Metallurgy,University of Maryland

[4]Dieter George E. 1987. Metalurgi Mekanik. Jakarta : Erlangga.

[5]Wiryosumarto, H, 2000. Teknologi Pengelasan Logam, Erlangga. Jakarta

[6]Sularso.2004. Dasar Perencanaan Dan Pemilihan Elemen Mesin: Pradnya Paramita Cetakanke XI.

[7]Novariandaru, A. 2014. Analisa Uji Visual dan Radiografi Pada Inspeksi Pengelasan Plat Baja Migas Cepu. Yogyakarta: Universitas Gadjah Mada. 